\title{
Reasons, Circumstances and Innovative Trends in Mobile Environments
}

\author{
Alin ZAMFIROIU, Mihai Liviu DESPA \\ Academy of Economic Studies, Bucharest, Romania \\ zamfiroiu@ici.ro,mihai.despa@yahoo.com
}

In this paper are presented the reasons why the sale of mobile devices has greatly increased in the last period. It is presented the evolution of mobile devices sales in the last 20 years. The main types of applications used today and how it will evolve in the near future. Development and using trends in mobile computing are presented. Key aspects of quality assurance in mobile application development projects are presented. Factors that influence the management process of a project are highlighted. A comprehensive analysis of the positive or negative impact that these factors exerts on the quality of the project is performed. Tools and methods used in the quality assurance process for mobile applications development are presented. The importance of quality assurance testing process is underlined.

Keywords: Mobile Applications, Trends, Mobile Environment, Development, Quality Assurance, Innovative

\section{Introduction \\ Mobile environment represented by mo- bile devices and mobile applications run on these devices has seen a big increase in re- cent years. According to [1] smart mobile device application development requires ex- tra attention from the developers. Important are issues that have led to this increase, the current circumstances of using the mobile applications and future trends of the use and development of mobile applications. The pa- per is structured as:}

Section The reasons for the accelerated growth of mobile devices usage shows the assumptions that have contributed to the explosive growth of mobile devices production. It also provides the evolution of mobile devices sales in the last 20 years for major manufacturers.

In section Current circumstances in internationally use of mobile applications are presented usage patterns of mobile applications currently. What types of applications are most used and the number of applications from online stores for these devices.

In section Development and usage trends of mobile applications the future trends of usage and mobile application development according to user requirements and within the restrictions imposed by mobile devices are presented.

Section Quality assurance tools in mobile application development projects present the quality management of the development process in the mobile environment. It also presented the factors which influence the quality of management in a mobile application development projects.

The paper ends with the section Conclusions.

\section{The Reasons for the Accelerated Growth of Mobile Devices Usage}

In 1973 the first mobile phone was launched by Motorola, Motorola DynaTAC model.

Their widespread use began in the '90s when they became available to the public. Production of mobile devices has had an explosive growth and completed a long way in only a few years. In [2] the evolution of mobile phone sales in the period 1992-2012 is presented. 20 years in the production of mobile phones due to competition and widespread use has increased not found in other electrical devices or technical productions.

In Table 1 for each year is highlighted the producer who was the leader of mobile device sales for that year. 
Table 1. Annual sales by manufacturers (millions)

\begin{tabular}{|c|c|c|c|c|c|c|c|c|c|c|c|}
\hline Year & NEC & Nokia & Motorala & Apple & Ericsson & Samsung & Siemens & Alcatel & LG & HTC & RIM \\
\hline $\mathbf{1 9 9 2}$ & 4 & 3 & - & - & - & - & - & - & - & - & - \\
\hline $\mathbf{1 9 9 3}$ & - & 5 & $?$ & - & - & - & - & - & - & - & - \\
\hline $\mathbf{1 9 9 4}$ & - & 9 & 12 & - & - & - & - & - & - & - & - \\
\hline $\mathbf{1 9 9 5}$ & - & 13 & $?$ & - & - & - & - & - & - & - & - \\
\hline $\mathbf{1 9 9 6}$ & - & 18 & $?$ & - & - & - & - & - & - & - & - \\
\hline $\mathbf{1 9 9 7}$ & - & 23 & $?$ & - & - & - & - & - & - & - & - \\
\hline $\mathbf{1 9 9 8}$ & - & 39 & 34 & - & 26 & 5 & - & - & - & - & - \\
\hline $\mathbf{1 9 9 9}$ & - & 77 & 48 & - & 30 & 18 & - & - & - & - & - \\
\hline $\mathbf{2 0 0 0}$ & - & 127 & 61 & - & 42 & 21 & 27 & - & - & - & - \\
\hline $\mathbf{2 0 0 1}$ & - & 140 & 60 & - & 27 & 29 & 40 & - & - & - & - \\
\hline $\mathbf{2 0 0 2}$ & 9 & 152 & 73 & - & 24 & 42 & 35 & 12 & 14 & - & - \\
\hline $\mathbf{2 0 0 3}$ & 15 & 182 & 76 & - & 27 & 55 & 44 & 8 & 27 & - & - \\
\hline $\mathbf{2 0 0 4}$ & - & 208 & 105 & - & - & 86 & 49 & - & 43 & - & 1 \\
\hline $\mathbf{2 0 0 5}$ & - & 265 & 145 & - & 52 & 104 & - & - & 55 & - & 4 \\
\hline $\mathbf{2 0 0 6}$ & - & 500 & 210 & - & 74 & 117 & 24 & - & 62 & - & - \\
\hline $\mathbf{2 0 0 7}$ & - & 436 & 165 & 2.3 & 102 & 154 & - & - & 79 & - & 10 \\
\hline $\mathbf{2 0 0 8}$ & - & 475 & 108 & 12 & 95 & 202 & - & - & 104 & - & 25 \\
\hline $\mathbf{2 0 0 9}$ & 5 & 442 & 59 & 24 & 57 & 238 & - & - & 124 & 11 & 35 \\
\hline $\mathbf{2 0 1 0}$ & - & 463 & 39 & 42 & 42 & 282 & - & 33 & 117 & 25 & 48 \\
\hline $\mathbf{2 0 1 1}$ & - & 422 & 40 & 89 & 33 & 330 & - & - & 86 & 48 & 52 \\
\hline $\mathbf{2 0 1 2}$ & - & 335.6 & - & 135.8 & - & 396.5 & - & - & 55.9 & 32.6 & - \\
\hline
\end{tabular}

Thus the period 1993-1997 was dominated by Motorola, although the actual number of terminals sold is not known. After 1997 followed the Nokia during which dominated the mobile phone market for 14 years, there are years in which the number of Nokia sold was two times the number of terminals sold by next producer. In 2007, the explosive growth in sales of Nokia has started to fall. This decrease came with the appearance on the market of mobile devices and the emergence of manufacturer Apple smartphones. This decrease began in 2007 continued until 2012 when Nokia lost leader position in the mobile market in favor of Samsung producer. These things are shown graphically in Figure 1.

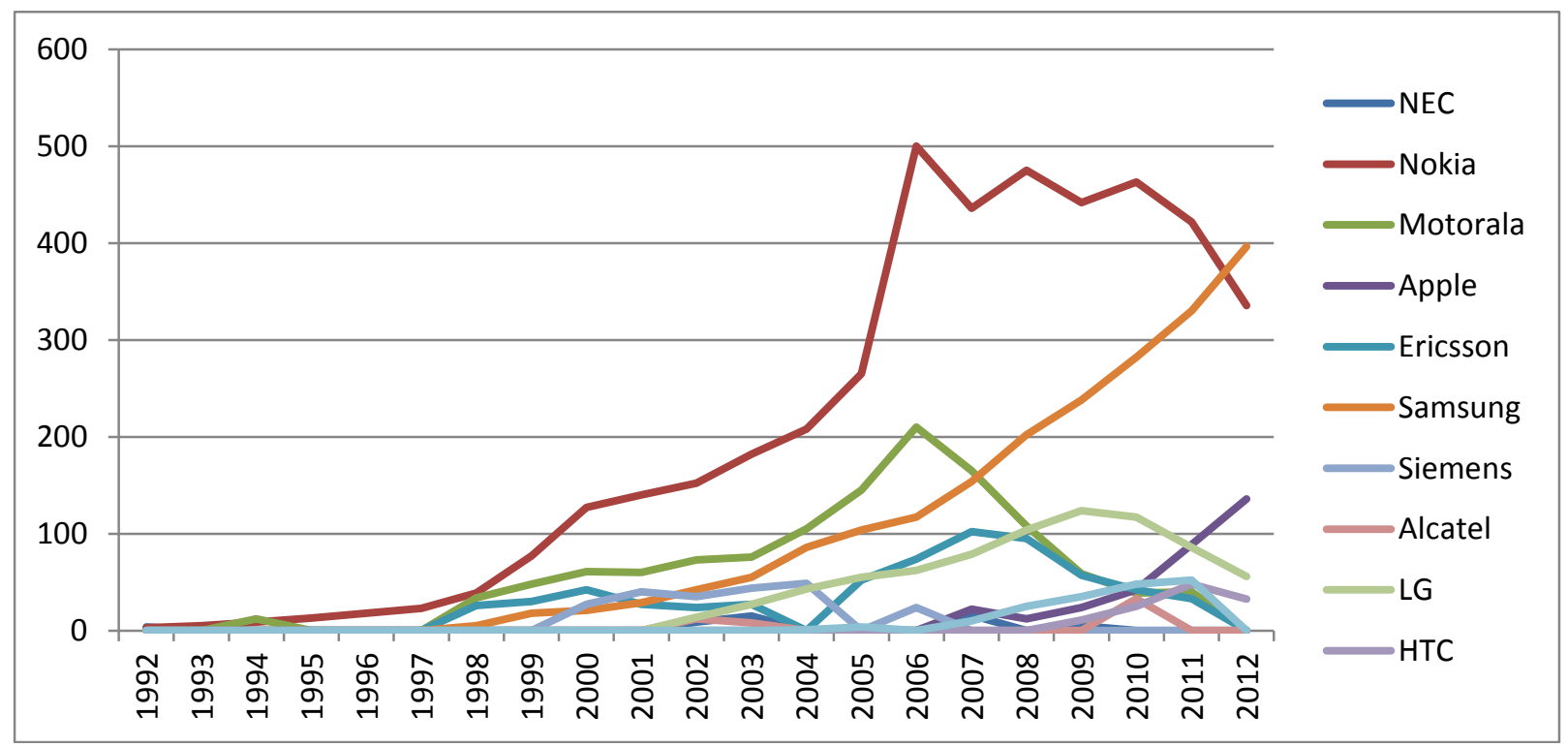

Fig. 1. Producers sales for 1992-2012 
In graph of Figure 1 is observed the domi- Sales growth of mobile devices in the 20 nance of the Nokia manufacturer on mobile years analyzed can be seen in Figure 2. devices market.

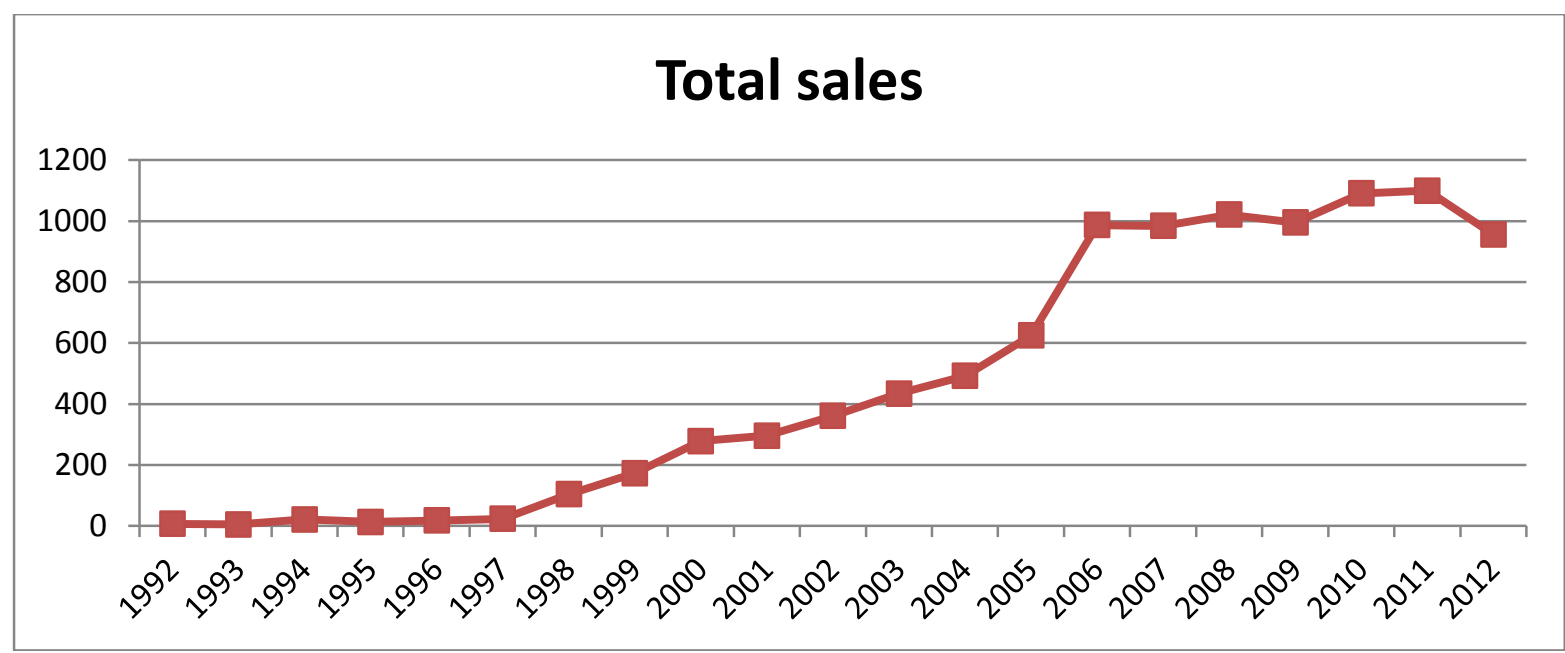

Fig. 2. Total sales for 1992-2012

In the graph in Figure 2 shows explosive growth, especially during 2003-2006.

3 Current Circumstances in Internationally Use of Mobile Applications

The multitude of mobile devices has caused the development of a large number of mobile applications. In [3] the main types of mobile applications and their level of use are pre- sented, Figure 3.

In Figure 3 is observed that the most frequently used applications are games, followed by social applications. Games are entertainment applications where users spend their free time in the public transportation or other places where they had to be expected something.

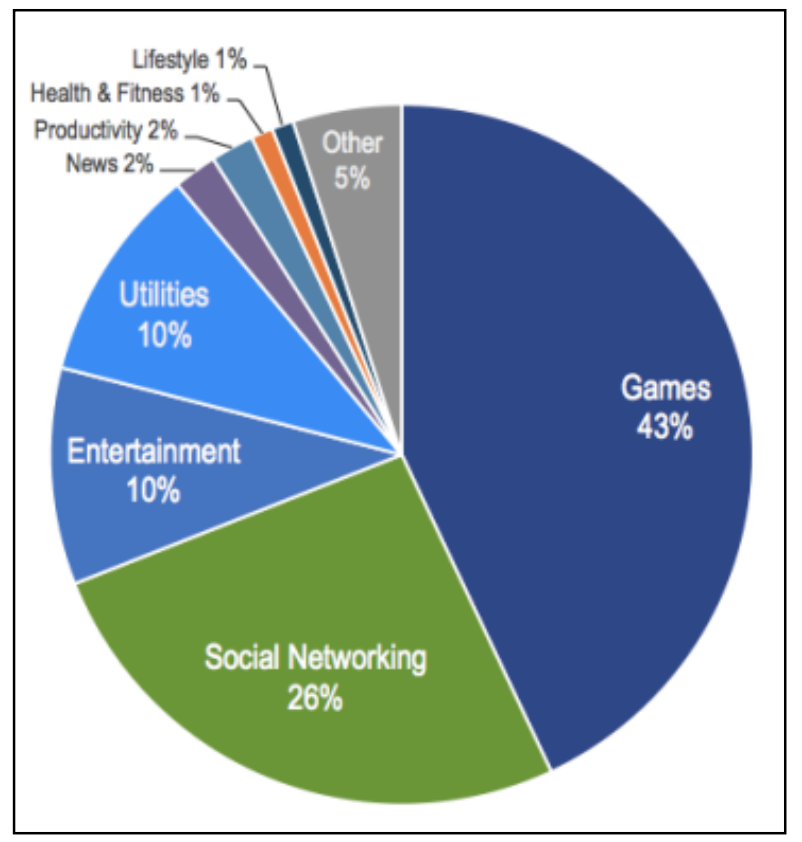

Fig. 3. Used types of applications [3]

In Figure 4 an overview of the number of applications loaded into the online stores of leading mobile application providers is presented. 


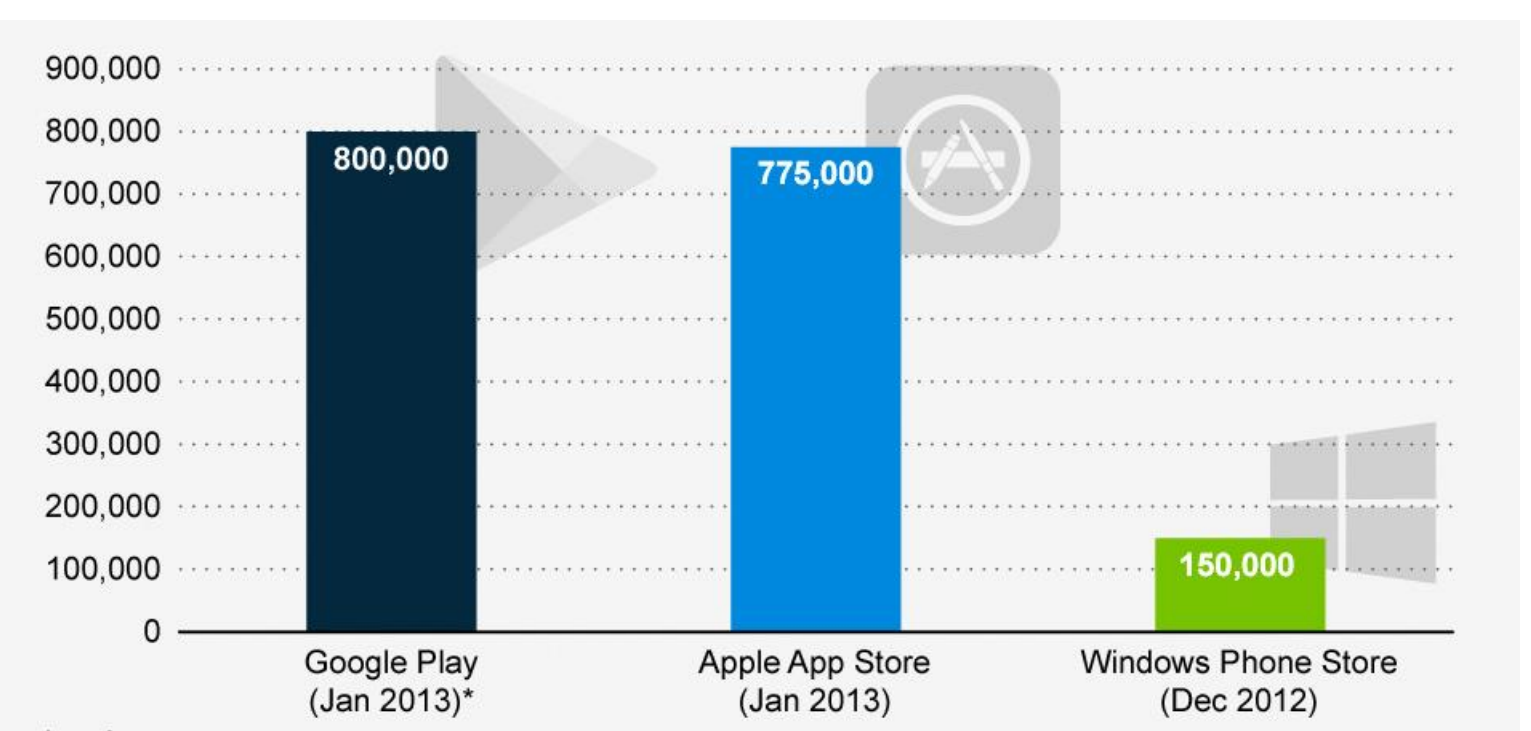

Fig. 4. Number of existing applications in online shops

On Google Play [4], an online shop for users of devices with the Android operating sys- tem, the most downloaded applications from free section are presented in Table 2.

Table 2. Top applications on Google Play

\begin{tabular}{|c|c|l|}
\hline Position & Application & \multicolumn{1}{c|}{ Description } \\
\hline 1 & Facebook & $\begin{array}{l}\text { Application used to connect to social network with the same } \\
\text { name. Provides tools for faster use certain features of the so- } \\
\text { cial network as well as adding photos or upload new statuses. } \\
\text { It also offers a direct notifications service on the phone. }\end{array}$ \\
\hline 2 & $\begin{array}{c}\text { Yahoo! } \\
\text { Messenger }\end{array}$ & $\begin{array}{l}\text { Social application which provides tools for communication via } \\
\text { voice and video. Enables communication with Facebook or } \\
\text { Windows Live users. It also provides tools for sending inter- } \\
\text { national SMS. }\end{array}$ \\
\hline 3 & $\begin{array}{c}\text { Crazy } \\
\text { Climber }\end{array}$ & $\begin{array}{l}\text { Is a 3D game in which the user performs jumps specific to the } \\
\text { parkour walking. It can jump up to the left or right over the } \\
\text { obstacles that appear randomly in the game. }\end{array}$ \\
\hline 5 & $\begin{array}{l}\text { Rhacing } \\
\text { It is a racing game. Provides the possibility to perform cars } \\
\text { upgrades. It offers the possibility to change them and adding } \\
\text { various devices to increase speed or for better aerodynamics of } \\
\text { the car. }\end{array}$ \\
\hline
\end{tabular}

Note that the number of applications downloaded look like socializing and games are the most used applications on mobile devices.

\section{Development and Usage Trends of Mo- bile Applications}

According to [5] CISCO estimates that in 2013 the number of mobile devices connect- ed to the Internet will exceed Earth's population, despite the fact that there are areas where people do not have such devices. In [6] three strategies for mobile application development are presented:

- native applications which are platformdependent and the SDK were developed but with access to all the device's hardware resources; 
- web applications developed to be run on a server and accessed by mobile devices via browsers, it provides limited access to the device's hardware resources and are available only online;

- hybrid applications developed to run on the mobile device and uses some module via the server, so some of the processing power is taken by the server, the device having the mission to present the results.

In [7] shown that in the coming years all providers operating system for mobile devices started to use HTML 5, CSS 3 and JavaScript for develop mobile applications. It will be available by using WebKit tool.

Mobile applications are trying to become web applications and accessed through browsers or hybrid applications. In these applications the processing power is moved on the server. Mobile devices are only used for user interaction.

In $[8,9]$ and innovative trends in the development of mobile devices are presented:

- converting data into actionable data which are provided depending on the geographical area where the user is positioned;

- widespread use of mobile payments;

- access to work tools on mobile devices, so employees will perform the work and is through mobile phones;

- distributing content between mobile devices or between them and the server to ensure the backups;

- screens becoming larger, approaching to the size of tablets;

- using of QR-codes to a large scale;

In this sense the development trend of mobile applications is to improve the usability and to be closer to the user by supporting it.

\section{Quality Assurance Tools in Mobile Ap- plication Development Projects}

The software development process is not a repetitive endeavour [10]. Each software application has distinct characteristics resulting from the way it was designed, the way the code was written and commented, the way testing was conducted or the development methodology that was used. For this reason, quality assurance cannot be organized and implemented in the same way as for production lines where repeating the same process and using the same steps can lead to empirically determine quality models and create relevant standards. Quality assurance in software development projects is oriented towards development and not towards production [10].

Quality assurance in mobile application development projects addresses the following issues:

- management quality

- development quality

- testing quality

\subsection{Management Quality}

In order to ensure the proper quality of the management process all the factors involved have to be thoroughly analyzed. The management process of mobile application development is influenced by the following factors:

- owner

- end-user

- project team

- legal framework

- competition

- previous experience

- market

- budget

- deadlines

In Figure 5 it is shown how various factors influence the quality of management in a mobile application development project. 


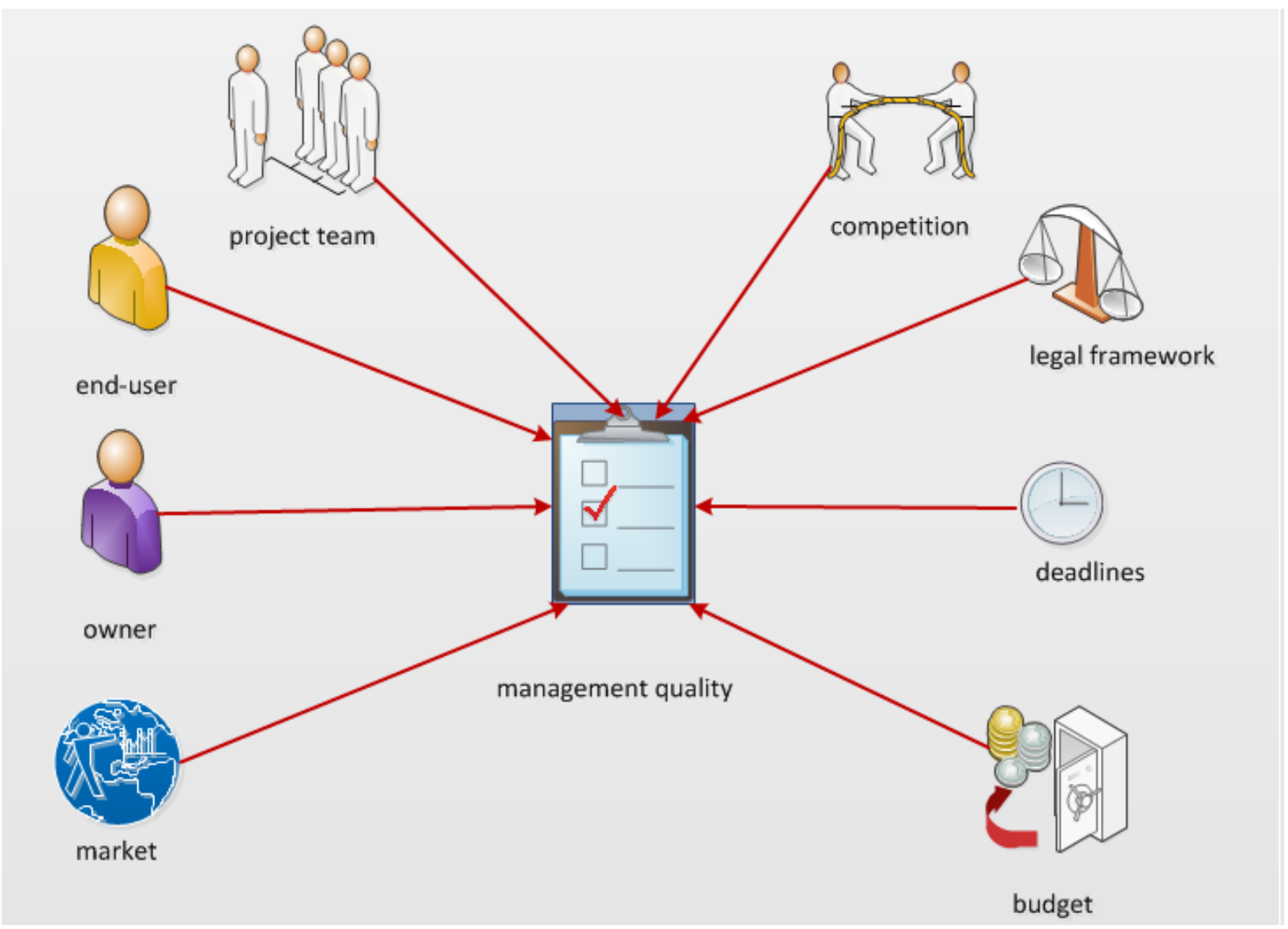

Fig. 5. Management process quality

Owner. The owner is the one who initiates, finances and benefits from the project. The owner and the project manager should not be confused as they are different entities even when developing an internal project [11]. The owner may adversely affect the quality of the project management processes by providing confusing or incomplete specifications. This leads the project manager to design unsuitable work scenarios and inaccurate project planning. During the development process of a mobile application, the owner is responsible for significant and frequent changes to initial project specifications. This causes delays, creates tension and discontent in the project team and generates additional costs. The owner can also have a negative impact on the project's quality by neglecting or delaying payments or by failure to provide adequate resources. In this type of scenario project development may be temporarily blocked creating yielding delays and additional costs.

End-user. The end-users are the actual peo- ple that are going to use the application on their mobile devices. The end-user influences positively the management quality of a mobile application development process by providing relevant feedback. If the project manager succeeds in obtaining relevant feedback concerning the application, then certain shortcomings can be corrected even during the planning or development stage. Based on the user's feedback the project manager can refine specifications and guide all development efforts towards the relevant functionalities. End-users are also becoming a significant force in the actual programming field. As stated by [12] end-users are developing their own applications, mostly for personal. These applications can provide valuable information about what end-users really require from mobile software.

Project team. The project team consists of all the persons actively involved in the project: project manager, programmers, testers, graphic designers and usability analysts. Project team members have a positive impact on 
the quality of project and on the quality of the management process when they make improvement proposals, optimization methods and innovative ideas. Project team are also the perfect example for synergy where collaborative work will ensure results significantly faster than individual work. The team members' efforts should be aligned to the project objective in order to achieve the best possible quality [13].

Legal framework. The legal framework is composed out of all the laws to which the project is subject to. The project management quality is adversely affected when a project is conducted in a coercive environment. The legal framework is constantly changing the way developers create and deliver applications. Legislation influences the way software is developed, used, reused, integrated and distributed [14]. Excessive bureaucracy harms management process as the project manager's efforts focus on legal formalities and less on the overall quality of the project.

Competition. Competition consists of mobile applications aimed at the same goal, that target the same audience or applications with similar functionalities to what is intended to be developed. The competition has a positive impact on the management process when making public data and reliable information about mobile applications previously launched. In this situation, the project manager can avoid mistakes made by competitors or can draw on their achievements.

Previous experience. Previous experience is composed of projects that the project manager has conducted in the past or on which implementation has participated. The project manager's past experiences can have a positive impact on the quality of the management process because they can provide inspiration and solutions when encountering common or similar elements. The project manager must transfer the previously acquired knowledge and experience of past projects onto the mobile application that has to be developed.

Market. The market is the aggregate of mobile application development defining envi- ronment elements. The management quality process is adversely affected by the speed at which technology is changing, the speed at which mobile terminals are lunched and the variety of technical characteristics. The project manager needs to know the latest technology in the market and adapt the development process to fit the software's short life cycle. Such applications should be developed at low cost and in extremely limited timespan often sacrificing quality.

Budget. The budget consists of all the material and financial resources raised in order to develop and implement the project. The budget is one of the most important constraints that a project manager must take into account when developing a mobile application. Apparently a project's budget should not affect the quality of management. A correctly sized budget will influence the overall management process quality by providing access to various tools that can be accessed only by paying a fee. Such tools are:

- project management software: Microsoft Project, Primavera Project Management;

- risk management software: @ Risk, Active Risk Manager;

- task assignment and progress racking software: Pivotal Tracker.

Deadlines. Deadlines are another critical constraint for the project managers and are often associated with milestones. Milestones are major landmarks for a project and mark the end of a planning, development or testing stage. These steps and milestones are also closely linked to payments made by the project owner. Any delay in delivering the application translates into payment delays and even penalties. Deadlines have a negative effect on the quality of management because they are a major stress factor for the project manager and team members. Declines often inhibit creativity and innovation. However deadlines help teams to focus on important tasks and mobilize people when the project is in a tight situation.

DOI: 10.12948/issn14531305/17.2.2013.09 
Table 3. Influencing factors of project management

\begin{tabular}{|c|c|c|}
\hline FACTORS & POSITIVE & NEGATIVE \\
\hline Owner & $*$ & $\begin{array}{l}\text { - confusing or incomplete } \\
\text { specifications } \\
\text { - change specifications } \\
\text { - late payments }\end{array}$ \\
\hline End-user & - feedback & $*$ \\
\hline Project team & - improvement proposals & $*$ \\
\hline Legal framework & $*$ & - excessive bureaucracy \\
\hline Competition & - provides data and information & $*$ \\
\hline Previous experience & $\begin{array}{l}\text { - source of inspiration } \\
\text { - knowledge and experience transfer }\end{array}$ & $*$ \\
\hline Market & $*$ & $\begin{array}{l}\text { - rapid technological change } \\
\text { - applications with short life } \\
\text { cycle }\end{array}$ \\
\hline Budget & $*$ & - management software tools \\
\hline Deadlines & - increase productivity & - inhibit creativity \\
\hline
\end{tabular}

\subsection{Development Quality}

The field of mobile applications development is one that has gained notoriety recently, which is why there is a relative lack of quality standards in the industry when it comes to the development process.

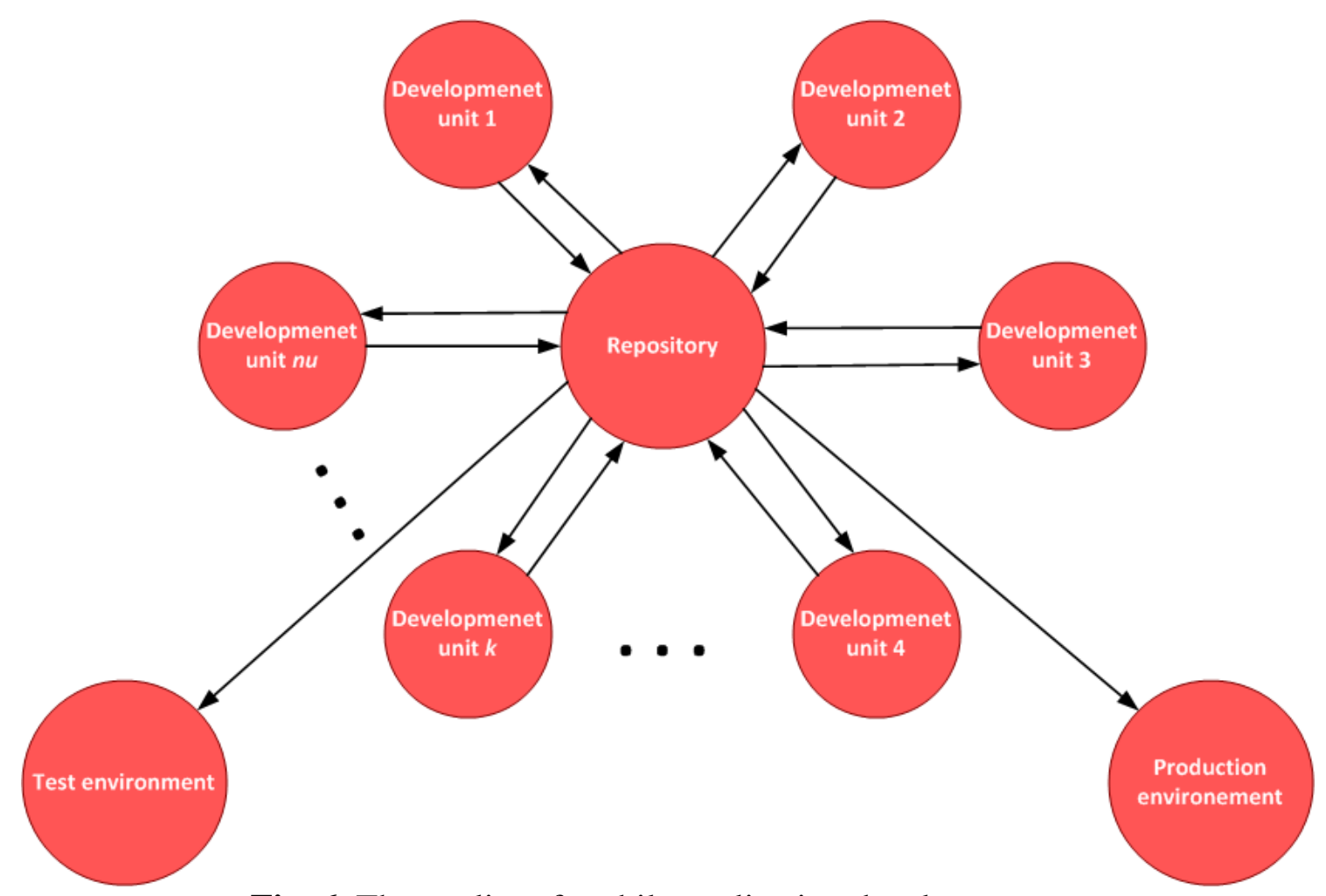

Fig. 6. The quality of mobile application development process

Each development unit is an entity composed of two elements: the programmer and development environment. The development envi- ronment can be hosted locally on the programmer's own machine, or online on a development server shared with other develop- 
ers. The production environment is the environment that will run the application. The test environment should be an exact replica of the production environment.

Consider $U d$ as the set of development units:

$$
U d=\left\{u d_{1}, u d_{2}, u d_{3} \ldots u d_{k} \ldots u d_{n u}\right\}
$$

Where:

$u d_{k}$ - is the development unit $k$ in a mobile

application development project

$n u$ - is the total number of development units

Consider $A_{k}$ as the set of updates performed

by a programmer:

$A_{k}=\left\{a_{k 1}, a_{k 2}, a_{k 3} \ldots a_{k i} \ldots a_{k n_{k}}\right\}$

Where:

$a_{k i}$ - is the update $i$ performed by development unit $k$

$n_{k}$ - is the number of updates performed by

development unit $k$

Consider $I_{k}$ as the set of source code up-

loads performed by a programmer:

$I_{k}=\left\{i_{k 1}, i_{k 2}, i_{k 3} \ldots i_{k j} \ldots i_{k m_{k}}\right\}$

Where:

$i_{k j}$ - is the upload $j$ performed by develop-

ment unit $k$

$m_{k}$ - is the total number of uploads per-

formed by development unit $k$

Under ideal conditions updates and uploads performed by development unit k must comply with the following rule:

$$
\sum_{i=1}^{n_{k}} a_{k i}=\sum_{j=1}^{m_{k}} i_{k j}
$$

This means that before starting work on a task the programmer representing development unit $k$ downloads the latest version of the source code. Also, for each completed task a single upload will be performed.

Under real development environment conditions uploads and updates performed by development unit $k$ comply with following rule:

$$
\sum_{i=1}^{n_{k}} a_{k i}<\sum_{j=1}^{m_{k}} i_{k j}
$$

This means that before starting work on a task the programmer representing development unit $k$ downloads the latest version of the source code. For each completed task multiple uploads will be performed.

The quality of mobile applications is strongly correlated with the degree of innovation that it incorporates. Innovative projects are those that define the standards and higher quality standards translate into more reliable and cheaper software.

\section{Conclusions}

Technology continues to develop in an alert, and programmers need to keep up with this development. In today's circumstances is not sufficient for a programmer to know one programming language for mobile applications development. Application development in the mobile environment requires knowledge of several programming languages and quality assurance during the development cycle.

Trends in the mobile environment are estimated based on the current requirements of the users that use mobile devices.

Quality assurance tools for mobile application development projects are focused on the management process, development process and testing process. The management process quality is ensured by identifying, analysing and prioritizing all factors of influence. Factors with negative influence have to be attenuated and controlled. Factors with positive influence have to be nurtured and promoted. To ensure the quality of the mobile application development process a flexible and rigours framework should be used. The framework should for multiple developers to simultaneously code on the same functionality, track application versions, track submission of source code and allow for environments total separation.

\section{References}

[1]L. Hall, A. Gordon, L. Newall, R. James, "A development environment for Intelligent Applications on Mobile Devices", Expert Systems with Applications, vol. 27, no. 3. 2004, pp. 481-492.

[2]http://en.wikipedia.org/wiki/List_of_bestselling_mobile_phones 
[3]http://www.smartinsights.com/mobilemarketing/mobile-marketinganalytics/mobile-marketing-statistics/

[4]https://play.google.com/store

[5]http://www.guardian.co.uk/technology/20

13/feb/07/mobile-internet-outnumberpeople

[6]M. Popa, "Frameworks for Mobile Applications Development", Proceedings of the 12th International Conference on Informatics in Economy, 25-28 April 2013, Bucharest, Romania, pp. 101-105.

[7]C. Toma, "Concepts Issues of Unified Mobile Distributed Computing Framework - U.M.D.C.F", Proceedings of the 12th International Conference on Informatics in Economy, 25-28 April 2013, Bucharest, Romania, pp. 131-137

[8]http://www.cmo.com/articles/2013/3/15/_ 6_mobile_marketing_.html

[9]http://www.themobilists.com/2013/01/22/ 2013-mobile-predictions/

[10] V. R. Basili, G. Caldiera - Improve software quality by reusing knowledge and experience, 2012, Sloan Management Review, vol. 37

[11] R. Muller, J. R. Turner - The impact of principal-agent relationship and con- tract type on communication between project owner and manager, 2005, International Journal of Project Management, vol. 23, pp. 398-403

[12] A. J. Ko, R. Abraham, L. Beckwith, A. Blackwell, M. Burnett, M. Erwig, C. Scaffidi, J. Lawrance, H. Lieberman, B. Myers, M. B. Rosson, G. Rothermel, M. Shaw, S. Wiedenbeck - The state of the art in end-user software engineering, ACM Computing Surveys, April 2011, vol. 43 , issue 3 .

[13] A. Cockburn - Agile software development, the people factor, The Agile Software Development Series Cockburn Highsmith Series Editors, 2001, pages 8889, Available at http://www.itu.dk/ oladjones/semester2/P roject $2 /$ materials/newmaterials/Agile\%20So ftware $\% 20$ development.pdf

[14] D. M. German, J. H. Webber, M. Di Penta - Lawful Software Engineering, Proceedings of the FSE/SDP workshop on Future of software engineering research, Santa Fe, New Mexico, USA, November 07 - 11, 2010 , pp. 129-132, ISBN: 9781-4503-0427-6.



Alin ZAMFIROIU has graduated the Faculty of Cybernetics, Statistics and Economic Informatics in 2009. In 2011 he has graduated the Economic Informatics Master program organized by the Academy of Economic Studies of Bucharest. Currently he works like a research assistant at "National Institute for Research \& Development in Informatics, Bucharest" and is PhD student in Economic Informatics at the Academy of Economic Studies. He has published as author and co-author of few journal articles and scientific presentations at conferences.

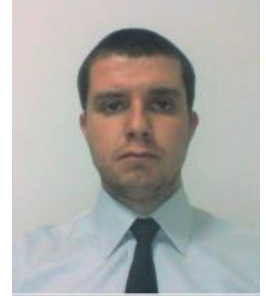

Mihai Liviu DESPA has graduated the Faculty of Cybernetics, Statistics and Economic Informatics from the Bucharest Academy of Economic Studies in 2008. He has graduated a Master's Program in Project Management at the Faculty of Management from the Bucharest Academy of Economic Studies in 2010. He is a PHD Student at the Economic Informatics PhD School and he is currently Project Manager at GDM Webmedia SRL. 